\title{
The Content, Quality, and Behavior Change Techniques in Nutrition-Themed Mobile Apps for Children in Canada: App Review and Evaluation Study
}

Jacqueline Marie Brown*, MHSc; Beatriz Franco-Arellano*, PhD; Hannah Froome, MHSc; Amina Siddiqi, MSc; Amina Mahmood, BHSc; JoAnne Arcand, RD, PhD

Faculty of Health Sciences, Ontario Tech University, Oshawa, ON, Canada

*these authors contributed equally

Corresponding Author:

JoAnne Arcand, RD, PhD

Faculty of Health Sciences

Ontario Tech University

2000 Simcoe Street North

Oshawa, ON, L1H 7K4

Canada

Phone: 19057218668

Email: joanne.arcand@ontariotechu.ca

\section{Abstract}

Background: Children increasingly use mobile apps. Strategies to increase child engagement with apps include the use of gamification and images that incite fun and interaction, such as food. However, the foods and beverages that children are exposed to while using apps are unknown and may vary by app type.

Objective: The aim of this study is to identify the app content (ie, types of foods and beverages) included in nutrition-themed apps intended for children, to assess the use of game-like features, and to examine app characteristics such as overall quality and behavior change techniques (BCTs).

Methods: This analysis used a cross-sectional database of nutrition-themed apps intended for children ( $\leq 12$ years), collected between May 2018 and June 2019 from the Apple App Store and Google Play Store (n=259). Apps were classified into four types: food games or nongames that included didactic nutrition guides, habit trackers, and other. Food and beverages were identified in apps and classified into 16 food categories, as recommended $(8 / 16,50 \%)$ and as not recommended $(8 / 16,50 \%)$ by dietary guidelines, and quantified by app type. Binomial logistic regression assessed whether game apps were associated with foods and beverages not recommended by guidelines. App quality, overall and by subscales, was determined using the Mobile App Rating Scale. The BCT Taxonomy was used to classify the different behavioral techniques that were identified in a subsample of apps $(124 / 259,47.9 \%)$.

Results: A total of 259 apps displayed a median of 6 (IQR 3) foods and beverages. Moreover, 62.5\% (162/259) of apps were classified as food games, $27.4 \%$ (71/259) as didactic nutrition guides, 6.6\% (17/259) as habit trackers, and 3.5\% (9/259) as other. Most apps $(198 / 259,76.4 \%)$ displayed at least one food or beverage that was not recommended by the dietary guidelines. Food game apps were almost 3 times more likely to display food and beverages not recommended by the guidelines compared with nongame apps ( $\beta=2.8 ; P<.001)$. The overall app quality was moderate, with a median Mobile App Rating Scale score of 3.6 (IQR 0.7 ). Functionality was the subscale with the highest score (median 4, IQR 0.3 ). Nutrition guides were more likely to be educational and contain informative content on healthy eating (score 3.7), compared with the other app types, although they also scored significantly lower in engagement (score 2.3). Most apps $(105 / 124,84.7 \%$ ) displayed at least one BCT, with the most common $\mathrm{BCT}$ being information about health consequences.

Conclusions: Findings suggest nutrition-themed apps intended for children displayed food and beverage content not recommended by dietary guidelines, with gaming apps more likely to display not recommended foods than their nongame counterparts. Many apps have a moderate app quality, and the use of consequences (instead of rewards) was the most common BCT.

(JMIR Mhealth Uhealth 2022;10(2):e31537) doi: 10.2196/31537 


\section{KEYWORDS}

mHealth; children; app quality; behavior change techniques; child nutrition; mobile apps; Canada; mobile phone

\section{Introduction}

\section{Background}

Establishing healthy eating patterns in early childhood promotes growth and development and reduces the risk of obesity and noncommunicable diseases [1-3]. This is also a time when habitual dietary patterns are established [4]. However, many children worldwide have poor quality diets [5-7]. In Canada, the average child has insufficient intakes of vegetables, fruit, and whole grain foods and consumes excess fat, sodium, and sugar [8,9], which is a dietary intake pattern strongly associated with childhood overweight, obesity, and chronic disease risk [10]. There are a multitude of factors that influence children's dietary attitudes, behaviors, and food choices, including intrinsic (eg, predisposed biological tendencies and gender) and extrinsic factors to children, such as the family (eg, mealtime and parenting style) and the community (eg, schools and media) [11]. Several strategies have been developed to improve child healthy eating habits including family and school-based interventions [12], nutrition policies [13,14], and the promotion of nutrition education, food skills, and food literacy [15]. These interventions can have profound health system and economic advantages [1,16].

Technology has evolved into a central part of everyday life $[17,18]$. In Canada and before the COVID-19 pandemic, over $25 \%$ of children spent more than 2.5 hours each day in front of a screen [19], with $99 \%$ of them having internet access outside of school. Almost a quarter of the children in grades 4 and 5 and half of the children in grade 7 owned a smartphone [20]. Studies have also demonstrated that children as young as 3 and 4 years old use their parents' smartphones between 25 and 50 minutes a day to watch television and videos, listen to music, and play games [20-23]. Children respond positively to fun and engaging challenges [24] that are captivating and motivating [25]. It is therefore understandable why games, advergames, and other digital activities are highly popular among children [26] and are substantively added to the digital marketplace [27].

Mobile health (mHealth), defined by the World Health Organization "as medical and public health practice supported by mobile devices, such as mobile phones, patient monitoring devices, personal digital assistants (PDAs), and other wireless devices" [28], is a convenient approach to support health promotion [29] and nutrition education among adults and children [17]. In particular, mHealth interventions have the potential to better engage youth about health-related topics, compared with traditional health interventions [17]. Among youth, mHealth apps have been found to increase fruit and vegetable intake [30-33], improve nutrition knowledge [32-34], promote food choice awareness and healthy eating behaviors $[35,36]$, reduce sugar intake [37], and improve physical activity [38]. Furthermore, mHealth apps, as part of multicomponent interventions, can be effective tools to improve and support health-related behaviors [38]. Previous research has demonstrated that app quality, such as the ability to customize an app and ease of use, influence the overall effectiveness of mHealth apps on health and behavioral outcomes [39-41]. Additional evidence indicates that the integration of appropriate behavior change techniques (BCTs) [42] into mHealth apps further enhances their effectiveness $[39,42,43]$. Although there is strong evidence to support the efficacy of mHealth apps designed and evaluated by health researchers, minimal research exists on the content, quality, and use of evidence-based BCTs of publicly available mobile apps with health-related content.

Given its relevance, there has been increasing interest in studying the use and content of mobile apps and mHealth interventions that are available to the public [22,39,44-46]. For example, one study showed that diet and nutrition apps have a higher proportion of advertisements in comparison with other general health and wellness apps [22]. Reviews of pediatric weight management, healthy eating, and physical activity mobile apps found that most lacked any integration of expert recommendations [44], and less than $1 \%$ underwent scientific evaluation [47]. Another study found that children and adolescents are frequently exposed to the advertisement of unhealthy foods when using social media apps [45]. However, the specific foods and beverages displayed in mobile apps intended for children that are not from advertisements have not yet been examined [38]. Even less is known about foods and beverages displayed in nutrition-themed apps that contain the highly engaging game-like features that attract children and youth. This concept is highly relevant as not all nutrition-themed apps are considered mHealth apps. In addition, with new apps becoming available almost every day, it has become difficult for users, as well as for health professionals and researchers, to identify, evaluate, and use high-quality mobile apps to support healthy habits.

\section{Objectives}

The aims of this study are 3-fold. First, we identified the app content (foods and beverages) included in different types of nutrition-themed apps intended for children and determined whether nutrition-themed apps with gaming features displayed more foods and beverages not recommended by dietary guidelines compared with nutrition-themed nongame apps. Second, we evaluated the overall quality of these apps using the Mobile App Rating Scale (MARS) [48], which is a "validated multidimensional measure of quality indicators" $[48,49]$. We also determined if app quality differed across the different types of nutrition-themed apps. Finally, we identified the different BCTs used in these apps, guided by a well-established taxonomy of such techniques [50].

\section{Methods}

\section{Study Design}

This research was a cross-sectional study that used a systematic search strategy and standardized evaluation process, modeled after comparable studies [51,52]. The Strengthening the 
Reporting of Observational Studies in Epidemiology checklist is presented in Multimedia Appendix 1.

\section{App Selection}

\section{Eligibility Criteria}

Apps were eligible for inclusion in the analysis if they contained nutrition content relevant to children (ie, not targeted to parents), were rated by the app developer as being appropriate for an audience aged $\leq 12$ years, were in the English language, were accessible to any user (ie, did not require an access code to use), were not affiliated with a brand or product, and were updated in the past 2 years. Excluded apps were simple food tracking apps (eg, calorie counting), chronic disease management apps (eg, diabetes), and apps that contained nutrition and food content irrelevant to dietary behaviors or education (eg, restaurant-themed time management games and word searches).

\section{App Search Strategy}

Between May 2018 and June 2019, apps were identified from the Canadian Apple App Store and Google Play Store, which are app retailers containing the greatest number of publicly available apps in Canada [27]. The search methodology used in this study was adapted from comparable studies that used multiple keywords and terms to conduct their searches [51,52]. A search of app categories was conducted using 16 unique search terms as follows: nutrition game, eating game, diet game, food education, food game, nutrition education, child nutrition, kids nutrition, kids food, kids healthy eating, health food, child health, kids health, health game, health education, and child education. The data extracted from the identified apps were title, developer, number of downloads (when available), and cost. All app information was entered into a database that was used throughout the screening, selection, and evaluation processes.

\section{App Screening, Selection, and Classification}

Identified apps first underwent screening for inclusion by 2 independent reviewers based on the title and developer. Duplicate apps, defined as apps appearing in both the Apple App Store and the Google Play Store, were identified and removed. Apps identified as relevant after the screening phase underwent a second independent review based on the detailed app description available in the respective app store. Those detailed descriptions determined if apps were eligible for inclusion in the analysis. Apps with a cost were purchased if they met the inclusion and exclusion criteria after reviewing the detailed descriptions. Apps were excluded from the study if they were removed from the marketplace before evaluation or if technical errors prevented a full evaluation (eg, app crashing). Disagreements at any stage of the app screening and evaluation process were resolved by a third independent reviewer.

The 4 app classifications (app types) were created using an inductive approach, which considered common app themes and characteristics observed during the review of apps, and 4 distinct classifications of apps were defined (Table 1). On the basis of their primary purpose, format, and core features, selected apps were classified into those four app types by two independent reviewers: food game, didactic nutrition guide, habit tracker, or other. Food games were defined as those that have implemented gamification techniques, such as rewards and competition, to engage the user in play involving food icons [53]. Nongame apps included didactic nutrition guides that provided information on food and nutrition to the user in written and picture format; habit trackers enabled users to log their food or drink intake [54] and apps classified as other did not contain any of the features nor had the primary purpose of the aforementioned app types.

Table 1. App types, definitions, and examples.

\begin{tabular}{|c|c|c|}
\hline App type & Definition & Examples \\
\hline Food game & $\begin{array}{l}\text { An app that implemented gamification techniques, such as } \\
\text { rewards and competition, to engage the user in play involving } \\
\text { food icons }\end{array}$ & $\begin{array}{l}\text { Dr Panda Restaurant } 2 \text { by Dr Panda Ltd; Strawberry } \\
\text { Shortcake Bake Shop by Budge Studios }\end{array}$ \\
\hline \multicolumn{3}{|l|}{ Nongame } \\
\hline $\begin{array}{l}\text { Didactic nutrition } \\
\text { guide }\end{array}$ & $\begin{array}{l}\text { An app that provided information on food and nutrition to the } \\
\text { user in written and picture format }\end{array}$ & $\begin{array}{l}\text { Nutrition Lookup by SparkPeople; SuperFoodsRx-Es- } \\
\text { sential Guide by SuperFoods Partners, LLC }\end{array}$ \\
\hline Habit tracker & An app that enabled users to log their food or drink intake & $\begin{array}{l}\text { Fooducate-Nutrition Tracker by Fooducate, Ltd; Water } \\
\text { Drink Reminder by Leap Fitness }\end{array}$ \\
\hline Other & $\begin{array}{l}\text { An app that did not contain the features or served the purpose } \\
\text { of a food game, didactic nutrition guide, or habit tracker }\end{array}$ & $\begin{array}{l}\text { Food \& Cooking Genius by Brainscape; LaLa Lunchbox } \\
\text { by LaLa Lunchbox }\end{array}$ \\
\hline
\end{tabular}

\section{App Evaluation}

Each app was downloaded and used for approximately 5 to 10 minutes for the reviewer to fully evaluate all aspects of the app content. In-app purchases were not evaluated in apps as these additional costs were determined to be largely inaccessible to the target audience of children. Apps were reviewed by 2 independent reviewers, and disagreements were resolved in consultation with a third independent reviewer.

\section{App Content Assessment}

\section{Foods and Beverages Displayed}

Foods and beverages displayed in apps were identified and classified into 16 food and beverage categories based on Canadian dietary guidelines, specifically the Canada's Food Guide (CFG) [55] and Canada's Dietary Guidelines [56]. Using the $\mathrm{CFG}$, food and beverage categories were further classified 
as recommended (ie, foods that should be consumed more often) and not recommended (ie, foods that should be limited):

- Recommended food and beverages: fruit, vegetables, whole grain foods, unprocessed meat, fish, meat alternatives, milk products, and milk alternatives

- Not recommended food and beverages: refined grain foods, sugar drinks, desserts, chocolate and candies, salty snacks, pizza, fast foods, and processed meat

Apps were also assessed to determine if foods and beverages differed between food game apps and those without gaming features (ie, didactic nutrition guide, habit tracker, and others). In addition, textual healthy eating messages, such as "eat as many different colors as you can at each meal," "eat breakfast every day, breakfast gives you energy and helps you think and learn" and "make at least half of your grain products whole grain each day," were also identified in the apps.

\section{Other Content Information}

The number of app downloads and app cost were also extracted from the Apple App Store or Google Play Store. The number of downloads was only extracted from apps available in the Google Play Store, as information on the number of downloads was not available from the Apple App Store.

\section{App Quality Assessment}

App quality was determined for the apps using the MARS [48]. The MARS contains 23 items divided into 5 subscales that also contain specific domains. Subscales of engagement (entertainment, interest, customization, interactivity, and target group), functionality (performance, ease of use, navigation, and gestural design), aesthetics (layout, graphics, and visual appeal), and information (accuracy of app description, goals, quality of information, quantity of information, visual information, credibility, and evidence base) were used to assess the objective quality of included apps [48]. The fifth subgroup, subjective quality (Would you recommend this app? How many times do you think you would use this app? Would you pay for this app? What is your overall rating of the app?), was not included because the apps were evaluated by researchers, not by the target audience of children; therefore, the subjective scores would not reflect the views of the intended audience. Each domain was rated by researchers on a 5-point Likert scale: 1=inadequate, $2=$ poor, $3=$ acceptable, $4=$ good, and 5=excellent. If a domain was not present in the app, that domain was rated as N/A and was not included in the domain subscale score. The average of all scores from each evaluated domain was considered as the overall app quality (MARS).

\section{BCT Assessment}

The use of different BCTs in apps was evaluated in a subsample of nongame nutrition apps, most likely to contain mHealth features, using the BCT Taxonomy (v1), developed by Michie et al [50]. This taxonomy identifies 93 hierarchically clustered techniques grouped within 16 behavioral clusters. Each app was evaluated for the presence or absence of each BCT listed in the taxonomy.

\section{Statistical Analyses}

Data were tested for normality, and descriptive statistics were used to calculate the number and proportion of foods and beverages and other information displayed in the apps, both overall and by app type. To assess differences in foods and beverages between food game apps and nongame apps, data from didactic nutrition guides, habit trackers, and other apps were combined. A binomial logistic regression assessed whether food game apps displayed more foods not recommended by dietary guidelines compared with nongame apps. The proportion of foods and beverages in food game apps and nongame apps was calculated by food category and chi-square-tested for differences between both groups.

The median and IQR were calculated for the MARS score, subscales, and domains. The Kruskal-Wallis test was used to evaluate differences in the MARS scores and subscales between the 4 different app types. The frequency and proportion of use of the different BCTs were calculated by cluster label and by specific behavioral component for the subsample of apps using descriptive statistics. Statistical significance was set at $P<.05$, except for the between-group comparisons of the MARS score (and subscales) and the 4 different app types, where $\alpha$ was set at $P<.01$, to account for multiple comparisons. Statistical analyses were conducted using RStudio software (RStudio) [57].

\section{Results}

\section{App Screening, Selection, and Classification}

After removing duplicates, a total of 2575 unique apps were identified during the app search phase (Figure 1). From the 1204 apps that underwent title and developer screening review, 259 apps were eligible for inclusion in the analysis (interrater percent raw agreement $=94.3 \%$ and Cohen $\kappa=0.88$ ). Multimedia Appendix 2 summarizes all included apps. Owing to the dynamic nature of the app marketplace, 60 apps were evaluated only by 1 reviewer, as these apps were removed from the marketplace during the app evaluation phase. For apps that were evaluated by 2 reviewers $(199 / 259,76.8 \%)$, app type classification yielded an interrater percent raw agreement of $91.7 \%$ and Cohen $\kappa$ of 0.87 . From the 259 apps, 162 (62.5\%) were classified as food games, $71(27.4 \%)$ as didactic nutrition guides, $17(6.6 \%)$ as habit trackers, and $9(3.5 \%)$ as other. 
Figure 1. PRISMA (Preferred Reporting Items for Systematic Reviews and Meta-Analyses) flow diagram for used to identify nutrition-themed apps intended for children.

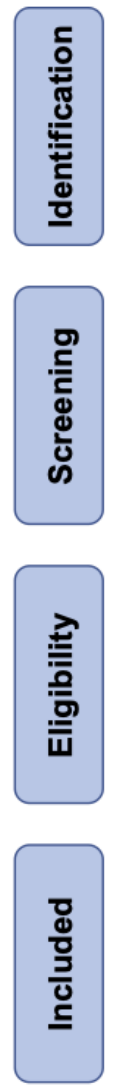

\section{App Content}

Among all 259 apps included in this analysis, apps included a median of 6 (IQR 3) food and beverage items. The most prevalent food and beverage items in the apps were fruit $(200 / 259,77.2 \%)$, milk products $(185 / 259,71.4 \%)$, vegetables $(179 / 259,69.1 \%)$, and unprocessed meats $(175 / 259,67.6 \%)$.

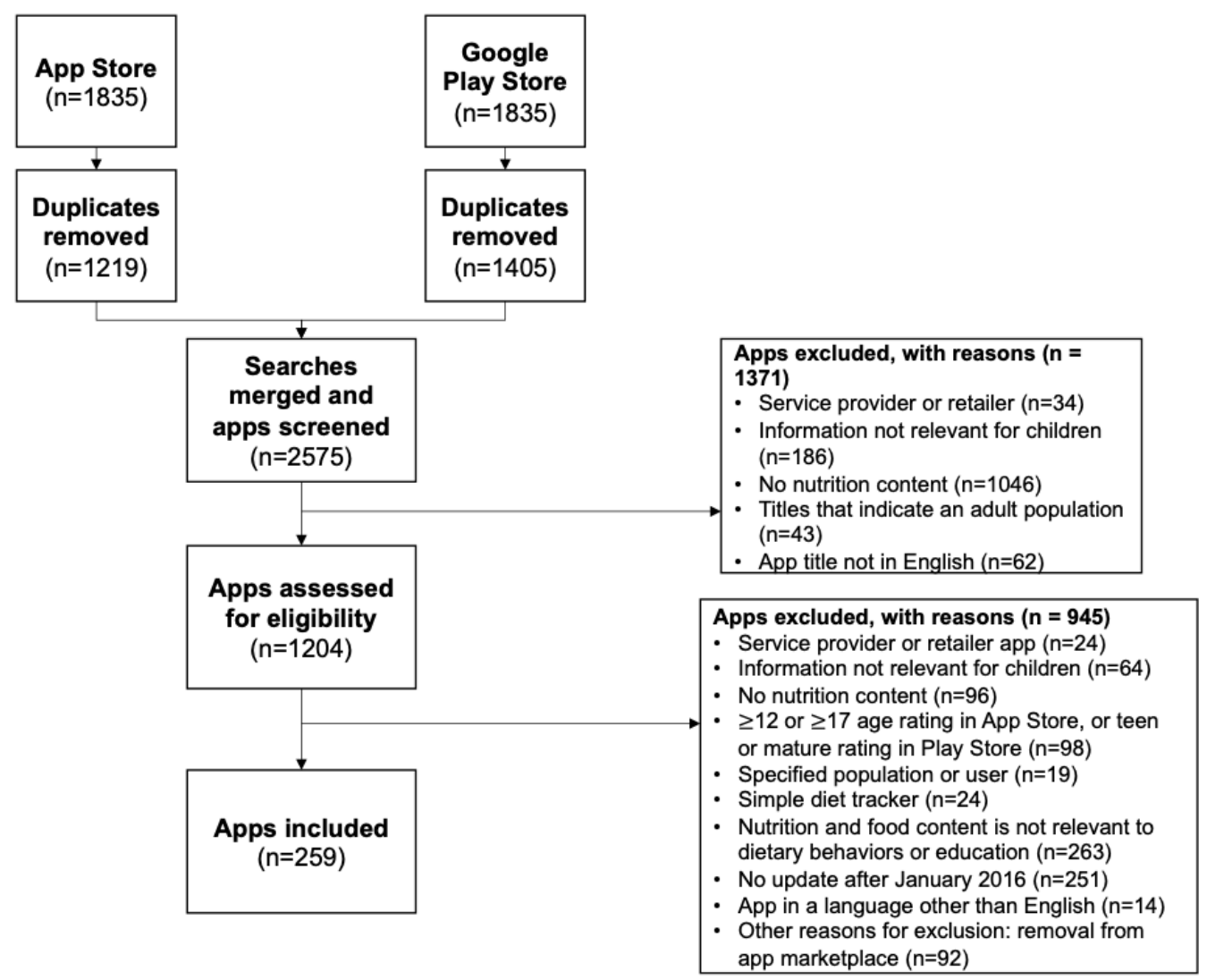

The least prevalent food items were salty snacks $(61 / 259$, $23.6 \%)$, fast foods $(57 / 259,22 \%)$, pizza $(51 / 259,19.7 \%)$, and milk alternatives $(38 / 259,14.7 \%$; Table 2$)$. Despite the high prevalence of foods recommended by dietary guidelines, only $28.9 \%(75 / 259)$ of the apps included explicitly healthy eating messages. 
Table 2. Types of food and beverages displayed in nutrition-themed apps for children.

\begin{tabular}{|c|c|c|c|c|c|}
\hline \multirow[t]{2}{*}{ Food and beverages } & \multicolumn{5}{|l|}{ Value, $\mathrm{n}(\%)$} \\
\hline & All $(\mathrm{n}=259)$ & Food game $(n=162)$ & Didactic nutrition guide $(\mathrm{n}=71)$ & Habit tracker $(n=17)$ & Other $(n=9)$ \\
\hline \multicolumn{6}{|c|}{ Presence of foods and beverages by category } \\
\hline \multicolumn{6}{|c|}{ Recommended by dietary guidelines ${ }^{a}$} \\
\hline Fruit & $200(77.2)$ & $110(67.9)$ & $68(95.8)$ & $14(82.4)$ & $8(88.9)$ \\
\hline Vegetables & $179(69.1)$ & $89(54.9)$ & $69(97.2)$ & $14(82.4)$ & $7(77.7)$ \\
\hline Whole grain foods & $81(31.2)$ & $13(8)$ & $53(74.6)$ & $14(82.4)$ & $1(11.1)$ \\
\hline Unprocessed meats & $175(67.6)$ & $95(58.6)$ & $62(87.3)$ & $13(76.5)$ & $5(55.6)$ \\
\hline Fish & $104(40.2)$ & $33(20.4)$ & $56(78.9)$ & $14(82.4)$ & $1(11.1)$ \\
\hline Meat alternatives & $110(42.5)$ & $29(17.9)$ & $63(88.7)$ & $14(82.4)$ & $4(44.4)$ \\
\hline Milk products & $185(71.4)$ & $110(67.9)$ & $56(78.9)$ & $14(82.4)$ & $5(55.6)$ \\
\hline Milk alternatives & $38(14.7)$ & $6(3.7)$ & $18(25.4)$ & $14(82.4)$ & $0(0)$ \\
\hline \multicolumn{6}{|c|}{ Not recommended by dietary guidelines ${ }^{a}$} \\
\hline Refined grain foods & $151(58.3)$ & $116(71.6)$ & $19(26.78)$ & $12(70.6)$ & $4(44.4)$ \\
\hline Sugary drinks & $92(35.5)$ & $62(38.3)$ & $15(21.1)$ & $15(88.2)$ & $1(11.1)$ \\
\hline Desserts & $103(39.8)$ & $75(46.3)$ & $10(14.1)$ & $14(82.4)$ & $4(44.4)$ \\
\hline Chocolate and candies & $133(51.4)$ & $108(66.7)$ & $9(12.7)$ & $14(82.4)$ & $2(22.2)$ \\
\hline Salty snacks & $61(23.6)$ & $38(23.4)$ & $6(8.4)$ & $14(82.4)$ & $3(33.3)$ \\
\hline Pizza & $51(19.7)$ & $29(17.9)$ & $7(9.8)$ & $14(82.4)$ & $1(11.1)$ \\
\hline Fast foods & $57(22)$ & $36(22.2)$ & $6(8.4)$ & $13(76.5)$ & $2(22.2)$ \\
\hline Processed meats & $81(31.3)$ & $57(35.2)$ & $8(11.3)$ & $13(76.5)$ & $3(33.3)$ \\
\hline \multicolumn{6}{|c|}{ Displayed at least one food or beverage not recommended by dietary guidelines } \\
\hline 0 food and beverage & $61(23.6)$ & $10(3.9)$ & $45(17.4)$ & $2(0.8)$ & $4(1.5)$ \\
\hline$\geq 1$ food and beverage & $198(76.4)$ & $152(58.7)$ & $26(10)$ & $15(5.8)$ & $5(1.9)$ \\
\hline Healthy messages & $75(28.9)$ & $13(8)$ & $51(71.8)$ & $8(47.1)$ & $3(33.3)$ \\
\hline App with cost & $35(13.5)$ & $12(7.4)$ & $16(22.5)$ & $3(17.6)$ & $4(44.4)$ \\
\hline Number of downloads & $121(46.7)$ & $73(45.1)$ & $34(47.9)$ & $11(64.7)$ & $3(33.3)$ \\
\hline
\end{tabular}

${ }^{a}$ Determined using categories and key messages provided by dietary guidelines (ie, Canada's Food Guide and Canada's Dietary Guidelines).

Overall, 46.7\% (121/259) of apps had data available on the number of downloads. The median number of downloads was 500,000 (IQR 4,990,000), with a range of 50 to $89,000,000$ downloads. Cost was evaluated for all apps, with $86.5 \%$ (224/259) of apps being free. The median cost for apps with a monetary charge was CAD $\$ 2.80$ (US $\$ 2.24 ; 35 / 259,13.5 \%$ ), with a range between CAD $\$ 1$ (US \$0.80) and CAD $\$ 8.50$ (US $\$ 6.80)$.

Food game apps, which comprised $62.5 \%$ (162/259) of apps overall, were almost 3 times as likely to display foods not recommended by dietary guidelines $(\beta=2.8 ; P<.001)$, compared with nongame apps (ie, didactic nutrition guides, habit trackers, and other). In particular, high-sugar foods, such as chocolates and candies $(P<.001)$ and desserts $(P=.008)$ were significantly more likely to be displayed in food game apps, as shown in Figure 2 (detailed information in Multimedia Appendix 3). Importantly, food game apps also displayed significantly lower proportions of recommended foods and beverages in almost all recommended food categories, except for milk products, which was not significantly different between groups. 
Figure 2. Proportion of foods and beverages displayed in food game apps and nongame apps by food category.

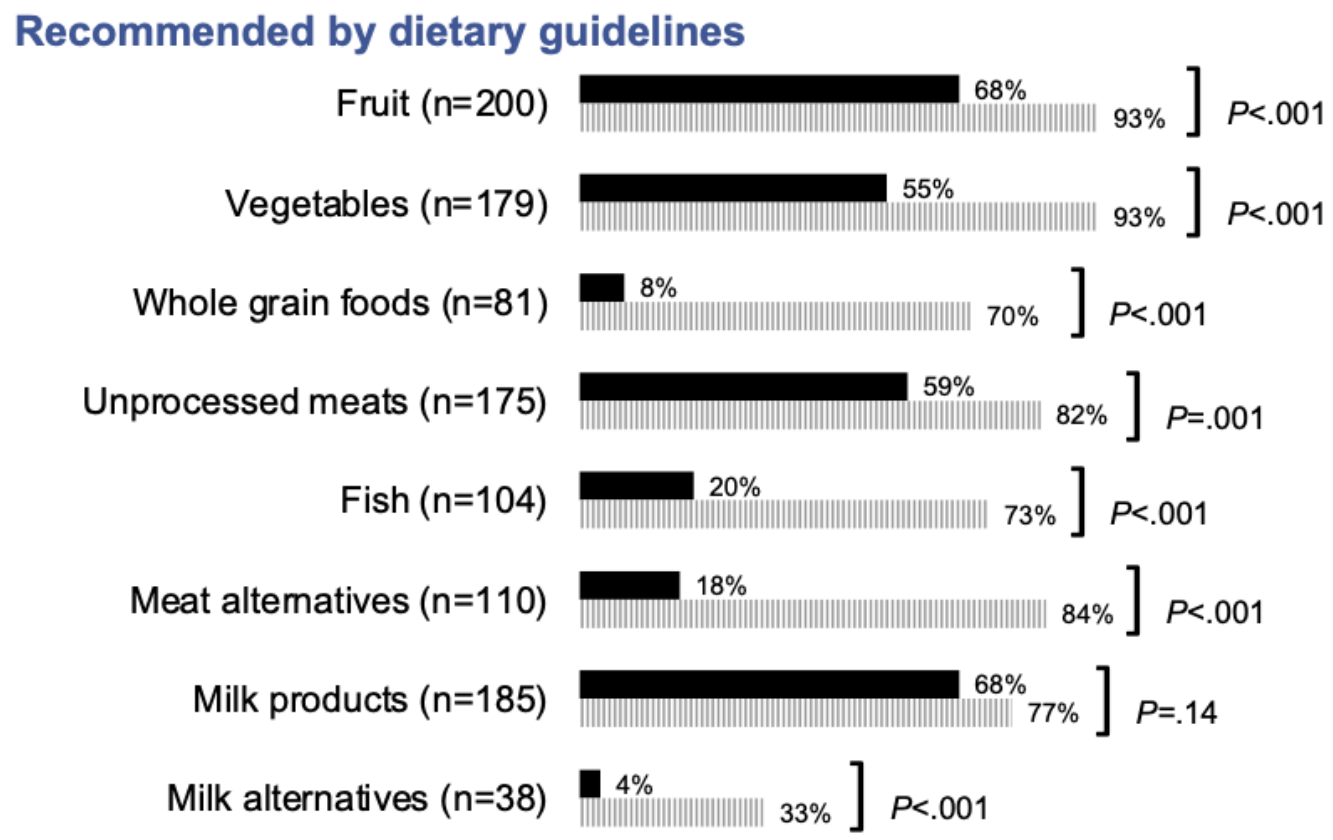

Not recommended by dietary guidelines

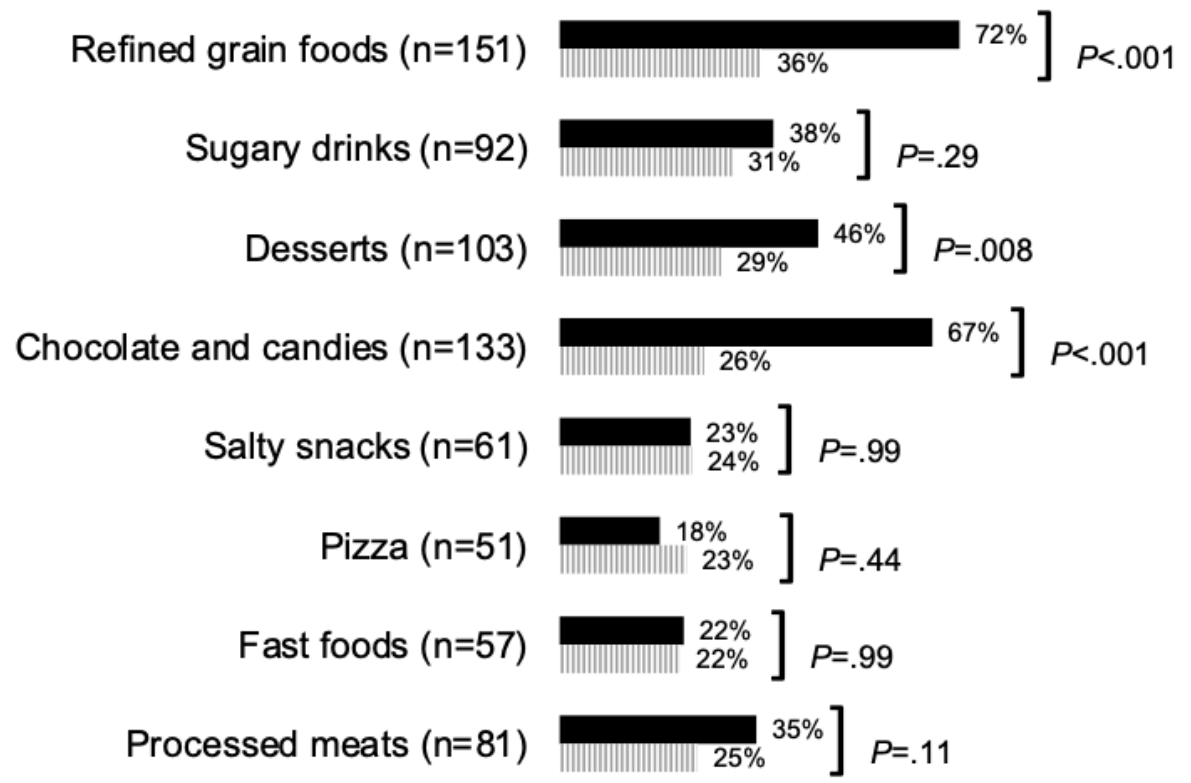

- Food game apps $(n=162) \quad$ I․ Nongame apps $(n=97)$

\section{App Quality}

The overall app quality was moderate, with a median MARS score of 3.6 (IQR 0.7; Table 3). There were significant differences in overall quality between the 4 types of apps, with nutrition guides only having a median MARS rating of 3.2 $(P<.001)$. Although nutrition guides were more likely to be educational and contain informative content on healthy eating (median score 3.7), compared with the other app types, they also scored significantly lower in overall engagement (score of 2.3) and in graphics and visual appeal (each with a score of 3 ). In addition, habit tracker apps were more likely to be engaging and aesthetic than were didactic nutrition guide apps. Overall, each subscale of the MARS was also moderate, with the highest ranked subscale being functionality (median 4, IQR 0.3), followed by aesthetics (median 3.7, IQR 0.7), information (median 3.6, IQR 1), and engagement (median 2.9, IQR 0.8). Although the information subscale received a moderate median 
MARS score, this average is likely magnified as many apps did not contain goals $(234 / 259,90.3 \%)$ or visual information $(238 / 259,91.9 \%)$, nor were they evaluated in available peer-reviewed literature $(258 / 259$, 99.6\%). Overall, larger differences between app types were seen in the engagement and aesthetics subscales.

Table 3. Quality of nutrition-themed apps for children, overall, and by app type ${ }^{\mathrm{a}}$.

\begin{tabular}{|c|c|c|c|c|c|c|}
\hline \multirow[t]{2}{*}{ App type } & \multicolumn{5}{|c|}{ Value, median (IQR) } & \multirow[t]{2}{*}{$P$ value } \\
\hline & $\begin{array}{l}\text { All } \\
(n=259)\end{array}$ & $\begin{array}{l}\text { Food game } \\
(\mathrm{n}=162)\end{array}$ & $\begin{array}{l}\text { Didactic nutrition } \\
\text { guide }(\mathrm{n}=71)\end{array}$ & $\begin{array}{l}\text { Habit tracker } \\
(\mathrm{n}=17)\end{array}$ & $\begin{array}{l}\text { Other } \\
(\mathrm{n}=9)\end{array}$ & \\
\hline Mobile App Rating Scale & $3.6(0.7)$ & $3.4(0.5)$ & $3.2(0.4)$ & $3.5(0.3)$ & $3.6(0.7)$ & $<.001$ \\
\hline Engagement & $2.9(0.8)$ & $3.0(0.8)$ & $2.3(0.7)$ & $3.3(0.5)$ & $3.1(1.4)$ & $<.001$ \\
\hline Entertainment & $3(1.5)$ & $2.5(2)$ & $3.0(0)$ & $3(0.6)$ & $3.5(1)$ & .02 \\
\hline Interest & $3(1)$ & $3(1.5)$ & $3(0)$ & $3(0.6)$ & $3(1)$ & .24 \\
\hline Customization & $3(1)$ & $3(0.5)$ & $1(2)$ & $4(0.5)$ & $3(3)$ & $<.001$ \\
\hline Interactivity & $3(1.5)$ & $3(0.5)$ & $1(2)$ & $4(0.5)$ & $3(2)$ & $<.001$ \\
\hline Target group & $3.5(1)$ & $4(0.5)$ & $3(1)$ & $3(0)$ & $4.5(1)$ & $<.001$ \\
\hline Functionality & $4.0(0.3)$ & $4.0(0.4)$ & $4.0(0.3)$ & $4.0(0.3)$ & $4.1(0.8)$ & .01 \\
\hline Performance & $4(0.5)$ & $4(0.5)$ & $4(0)$ & $4(0.6)$ & $4(0.5)$ & .01 \\
\hline Ease of use & $4(0)$ & $4(0.1)$ & $4(0.5)$ & $4(0)$ & $4.5(1)$ & .002 \\
\hline Navigation & $4(0)$ & $4(0)$ & $4(0)$ & $4(0)$ & $4(1)$ & .03 \\
\hline Gestural design & $4(0.5)$ & $4(0.5)$ & $4(0)$ & $4(0)$ & $4(1)$ & .008 \\
\hline Aesthetics & $3.7(0.7)$ & $3.7(0.7)$ & $3.3(0.5)$ & $4(0.6)$ & $4(0.3)$ & $<.001$ \\
\hline Layout & $4(0.5)$ & $4(0.5)$ & $4(0.5)$ & $4(0.5)$ & $4(0)$ & .007 \\
\hline Graphics & $3.5(1)$ & $3.5(1)$ & $3(0.5)$ & $4(0.6)$ & $4(0)$ & $<.001$ \\
\hline Visual appeal & $3.5(1)$ & $3.5(1)$ & $3(0.8)$ & $4(0.6)$ & $4(1)$ & $<.001$ \\
\hline Information & $3.6(1)$ & $3.5(1.3)$ & $3.7(0.3)$ & $3.5(0.4)$ & $3.3(0.9)$ & .22 \\
\hline Accuracy & $4(0.5)$ & $4(0.5)$ & $4(0)$ & $4(0)$ & $4(0)$ & .19 \\
\hline Goals & $3(0.5)$ & $3(1)$ & $3(0)$ & $3(0.5)$ & $3(0.5)$ & .46 \\
\hline Quality & $4(0.8)$ & $3(0.1)$ & $4(0)$ & $4(0)$ & 4. $(0.5)$ & $<.001$ \\
\hline Quantity & $4(1)$ & $3(1)$ & $4(0.5)$ & $3.5(0.5)$ & $3(1)$ & $<.001$ \\
\hline Visual & $4(1)$ & $3.5(1)$ & $3.5(1)$ & $4(0)$ & $4(0)$ & .33 \\
\hline Credibility & $1(2)$ & $1(0)$ & $3(1)$ & $3(2)$ & $1(1.5)$ & $<.001$ \\
\hline Evidence-based $^{\mathrm{c}}$ & $\mathrm{N} / \mathrm{A}^{\mathrm{d}}$ & N/A & N/A & N/A & N/A & N/A \\
\hline
\end{tabular}

${ }^{\mathrm{a}}$ The 23-item Mobile App Rating Scale was used to assess the quality of the included apps on 4 subscales of engagement (5 domains), functionality (4 domains), aesthetics ( 3 domains), and information (7 domains). Each domain was rated on a 5-point Likert scale: 1=inadequate, $2=$ poor, $3=$ acceptable, $4=$ good, and $5=$ excellent. If a domain was not present in the app, that domain was rated as N/A. The average of all scores from each evaluated domain was considered as the overall app quality.

${ }^{\mathrm{b}}$ Significant difference was set at $P<.01$ to account for multiple comparisons and determined by the Kruskal-Wallis test.

${ }^{\mathrm{c}}$ Not evaluated as the number of responses was $<5$.

${ }^{\mathrm{d}} \mathrm{N} / \mathrm{A}$ : not applicable.

\section{BCT Assessment}

BCTs were identified in $84.7 \%$ (105/124 subsample) of apps that were evaluated. Among those, $72.4 \%$ (76/105) had 1 or 2 BCTs, 22.9\% (24/105) had between 3 and 10 BCTs, and we also found $4.8 \%$ (5/105) of apps with more than 10 BCTs. The most common BCT clusters among the 105 apps were natural consequences (100/105, 95.2\%), shaping knowledge (49/105, $46.7 \%)$, and goal setting and planning (47/105, 44.8\%). The most common individual BCTs identified in apps were information about health consequences (92/105, 87.6\%), followed by instructions on how to perform a behavior (49/105, 46.7\%; see Table 4 for detailed information). 
Table 4. Frequency of behavior change techniques (BCTs) identified in a sample of apps intended for children ( $\mathrm{n}=105)^{\mathrm{a}}$.

\begin{tabular}{|c|c|}
\hline BCT cluster label and component & Frequency, $\mathrm{n}(\%)$ \\
\hline Goal setting and planning & $47(44.8)$ \\
\hline Goal setting (behavior) & $16(15.2)$ \\
\hline Problem Solving & $1(0.9)$ \\
\hline Goal setting (outcome) & $12(11.4)$ \\
\hline Action planning & $7(6.7)$ \\
\hline Review behavior goals & $6(5.7)$ \\
\hline Review outcome goals & $5(4.8)$ \\
\hline Feedback and monitoring & $36(34.3)$ \\
\hline Feedback on behavior & $11(10.5)$ \\
\hline Self-monitoring of behavior & $12(11.4)$ \\
\hline Self-monitoring of outcome of behavior & $10(9.5)$ \\
\hline Feedback on outcome of behavior & $3(2.9)$ \\
\hline Social support & $3(2.9)$ \\
\hline Social support (unspecified) & $3(2.9)$ \\
\hline Shaping knowledge & $49(46.7)$ \\
\hline Instruction on how to perform a behavior & $49(46.7)$ \\
\hline Natural consequences & $100(95.2)$ \\
\hline Information about health consequences & $92(87.6)$ \\
\hline Information about social and environmental-consequences & $2(1.9)$ \\
\hline Information about emotional consequences & $6(5.7)$ \\
\hline Comparison of behavior & $11(10.5)$ \\
\hline Demonstration of the behavior & $11(10.5)$ \\
\hline Associations & $11(10.5)$ \\
\hline Prompts cues & $11(10.5)$ \\
\hline Repetition and substitution & $4(3.8)$ \\
\hline Behavior substitution & $2(1.9)$ \\
\hline Habit formation & $1(0.9)$ \\
\hline Graded tasks & $1(0.9)$ \\
\hline Comparison of outcomes & $4(3.8)$ \\
\hline Credible source & $4(3.8)$ \\
\hline Regulation & $2(1.9)$ \\
\hline Reduce negative emotions & $1(0.9)$ \\
\hline Conserving mental resources & $1(0.9)$ \\
\hline Identity & $2(1.9)$ \\
\hline Identification of self as role model & $2(1.9)$ \\
\hline
\end{tabular}

${ }^{\mathrm{a}}$ Identified using the behavior change technique taxonomy developed by Michie et al [50].

\section{Discussion}

\section{Principal Findings}

This study is among the first to identify and empirically evaluate foods and beverages displayed in nutrition-themed apps intended for children in publicly available app stores. Most apps displayed foods and beverages not recommended by dietary guidelines (especially among those apps with game-like features), which had a moderate app quality. Importantly, this study also identified the use of consequences, rather than rewards, as the most common BCT in apps most likely to contain mHealth features. 
Apps displayed a median of 6 food or beverage items to children, and the majority $(198 / 259,76.4 \%)$ displayed foods and beverages not recommended by dietary guidelines. This finding is concerning as it is likely a conservative estimate of exposure to food products that are not recommended by dietary guidelines in apps. This study excluded apps from branded products and did not evaluate in-app advertisements by food companies, which could have largely increased the number of displayed foods and beverages that are not recommended by dietary guidelines [45]. It was not surprising that the types of foods and beverages differed by app type. For example, nutrition guides, which are informative and educational in nature, displayed more fruit, vegetables, meat alternatives, and milk products, whereas habit tracker apps displayed large amounts of both foods recommended and not recommended by dietary guidelines. In addition, the nutrition guide apps were found to be of lower overall quality, which was largely the result of having fewer engaging features and lower quality graphics and visual appeal. Of notable concern was that food game apps were more likely to display unhealthy foods to children, such as chocolates, candies, and desserts. They also displayed significantly fewer recommended foods compared with nongame apps. This finding concurs with other studies that have found that the food content in apps may not align with dietary recommendations and lack evidence-based health information $[40,44,58,59]$. Childhood is the formative life stage when food and nutrition preferences, attitudes, and habits are learned [13], which are traits known to carry over into adulthood [60]. The latter highlights the importance of enhancing healthy eating and nutrition knowledge at an early life stage [17]. As children are more likely to be exposed and influenced by web-based media platforms [26,61,62], especially high-quality and engaging apps [24], it is critical that app developers limit the use of unhealthy foods in mobile game apps for children $[26,63,64]$. Although nongame apps displayed food and beverage items that are recommended by dietary guidelines, their limited ability to engage users indicates that they are unlikely to positively influence healthy eating behaviors.

Although nutrition guides may benefit children from an educational standpoint, this study found that they may be less attractive and engaging for children based on their design features. This finding is relevant because there is significant potential for mobile apps that can be used to deliver engaging and high-fidelity interventions to educate and motivate children about healthy eating practices [65]. Several studies have emphasized the potential positive role of mHealth apps as cost-effective [46], low burden interventions to promote healthy eating, self-monitoring, and behavior change [66,67]. For instance, serious games (ie, digital games designed for educational purposes) have been found to support children's increased vegetable and fruit intake [30-33], knowledge of macronutrients [32,33], food choice skills [35], and reduced sugar intake [37]. Moreover, healthy eating messaging can be incorporated into apps. Although our study found that only $8 \%$ (13/162) of food game apps contained messages aligned with dietary guidelines, $72 \%(51 / 71)$ of didactic nutrition guides and $42 \%$ (8/17) of habit trackers displayed healthy eating messages. These findings suggest that it is possible to use apps as a vehicle to support healthy eating messaging and nutrition education, as it has been used in other areas such as physical and mental health $[68,69]$. However, many apps on the marketplace would require modifications to align messaging with dietary guidelines and to include elements to increase their overall quality (visual appeal, graphics, engaging features, and BCTs). As nutrition guide and habit tracker apps may not be highly engaging for children, integrating gaming elements into these educational and informative apps may be more impactful in promoting the uptake of healthy eating knowledge and behaviors [41,70]. An example of a game-based nutrition education app is Foodbot Factory [71], which was designed to teach children about CFG and positively influenced children's knowledge of CFG guidelines [34].

Importantly, the efficacy of mHealth interventions can be significantly impacted by overall app quality [48] and the integration of suitable theory-based BCTs [50]. The MARS, for instance, has been used to identify high-quality medication reminder apps [72]. However, a lack of initial and sustained engagement has also been identified as a key constraint that limits digital nutrition promotion interventions [73]. In this study, we found that the overall quality of the apps, as evaluated by the MARS, was moderate, with apps receiving a median quality score of $3.6 / 5$. These results underline the need to integrate engagement and motivation cues, factors known to strongly influence how long children will interact with an app [24]. Most apps also used information about health consequences as a BCT, which seems to be an unsupported tactic to induce behavior change (and less useful among children), compared with incentivization of positive health behaviors (ie, the use of points and rewards) [74]. Furthermore, limited evidence exists on user testing [73] and the assessment of app effectiveness in terms of user satisfaction [22]. Thus, the development of effective and engaging mHealth apps not only requires evidence-based content and appropriate BCTs but also necessitates the feedback of end users and evaluation of effectiveness through appropriately designed studies.

\section{Limitations}

There are limitations to this study. It may be argued that a search of this kind cannot be truly systematic because of the dynamic nature of the app marketplace and limited search and data extraction abilities $[75,76]$. However, the use of multiple search terms to identify apps allowed this search to reach saturation and capture the most common nutrition apps targeted to children. Although paid apps were included in this study when free apps contained in-app purchases, only the free content was analyzed because the use of in-app purchases is likely to be less accessible to our target audience of children and adolescents; this decision may have resulted in an underestimation of the foods and beverages included. In addition, for this analysis, information on data privacy was not assessed. Assessments of data privacy policies and procedures are critically important, especially when apps are targeted to children; however, this information was not publicly available at the time of data collection. Although the Apple App Store added information on data privacy in June 2020, the Google Play Store has not, as of January 2022. Finally, because of its cross-sectional design, this study does not allow us to determine the relationship between exposure to foods and beverages displayed in apps (particularly those not 
recommended by dietary guidelines) and children's health, or their knowledge, attitudes, and behaviors related to such foods. However, describing the exposure is a first step to investigating this relevant topic, and this should be a focus of future research.

\section{Comparison With Prior Work}

An earlier comparable study by Schumer et al [22] examined publicly available diet and nutrition apps available in the Google Play Store ( $n=86$ apps that were relevant for any age group), identified the focus of apps (eg, education, tracking, and planning), diet types (eg, Paleo diet), and app features (eg, goal setting and feedback). In capturing this information, the authors described initial factors that potential users evaluate when deciding to use an app [22]. An Australian study used a comparable approach to evaluate food and nutrition-related mobile apps to support healthy family food provision [40]. This study found that apps targeting parents with children had an app quality score of 3.5 , similar to our results; however, many apps also had poor engagement. This study builds upon the previous work by conducting an in-depth evaluation of the different foods and beverages displayed in apps and whether or not these foods and beverages met dietary guidelines. This study's novelty further expands our understanding of apps intended solely for children and not parents or adults in general. In addition, our study goes beyond the findings of Schumer et al [22] in the assessment of apps intended for children by identifying those that were games, which is critical to examine as gaming apps are highly influential among youth [17,46]. A major strength of this study was the use of standardized evaluation and classification of apps, which was conducted independently by 2 reviewers, with a third independent reviewer to resolve disagreements. This process ensured a rigorous evaluation of the app content and classification. Another major strength was the use of the 2 major app stores, in contrast to the study by Schumer et al [22], which only involved 1 app store.

\section{Conclusions}

This research demonstrated that nutrition-themed apps intended for children displayed many foods and beverages not recommended by dietary guidelines, and food game apps were more likely to display unhealthy foods and beverages compared with nongame apps. We also found that many of these apps in the subsample have a moderate app quality, and most of them use information about health consequences as a BCT. Nevertheless, given their popularity, nutrition-themed game apps have the potential to be used by health professionals, researchers, educators, and app developers to create evidence-based apps for children that align with dietary guidelines, which can be used to encourage healthy eating habits. Future research is required to broaden our understanding of how youth use and interact with apps containing nutrition content, their influence, and possible use for promoting nutrition education and healthy eating.

\section{Acknowledgments}

This study was funded by an Ontario Research Fund-Research Excellence Grant (RE08-092). The authors thank Mohammed Tayyib Khan for his contributions to this research.

\section{Authors' Contributions}

JA and JMB contributed to the conceptualization and design of the study. JMB, HF, AS, and AM collected and extracted data. BF-A analyzed the data and drafted the final manuscript. JA supervised and oversaw all aspects of the study. All authors provided critical revisions for intellectual content and read and approved the final version.

\section{Conflicts of Interest}

None declared.

\section{Multimedia Appendix 1}

Strengthening the Reporting of Observational Studies in Epidemiology Statement—checklist of items that should be included in reports of observational studies.

[DOCX File, 25 KB-Multimedia Appendix 1]

\section{Multimedia Appendix 2}

Summary of nutrition apps included in the analysis $(n=259)$.

[DOCX File, 48 KB-Multimedia Appendix 2]

\section{Multimedia Appendix 3}

Proportion of foods and beverages displayed in food game apps and nongame apps by food category ( $\mathrm{n}=259)$. [DOCX File, 16 KB-Multimedia Appendix 3]

\section{References}

1. Clark H, Coll-Seck AM, Banerjee A, Peterson S, Dalglish SL, Ameratunga S, et al. A future for the world's children? A WHO-UNICEF-Lancet Commission. Lancet 2020 Feb;395(10224):605-658. [doi: 10.1016/s0140-6736(19)32540-1] 
2. Hurley K, Yousafzai A, Lopez-Boo F. Early Child Development and Nutrition: A Review of the Benefits and Challenges of Implementing Integrated Interventions. Adv Nutr 2016 Mar;7(2):357-363 [FREE Full text] [doi: 10.3945/an.115.010363] [Medline: 26980819]

3. Barouki R, Gluckman PD, Grandjean P, Hanson M, Heindel JJ. Developmental origins of non-communicable disease: implications for research and public health. Environ Health 2012 Jun 27;11:42 [FREE Full text] [doi:

10.1186/1476-069X-11-42] [Medline: 22715989]

4. Craigie AM, Lake AA, Kelly SA, Adamson AJ, Mathers JC. Tracking of obesity-related behaviours from childhood to adulthood: a systematic review. Maturitas 2011 Nov;70(3):266-284. [doi: 10.1016/j.maturitas.2011.08.005] [Medline: 21920682]

5. Afshin A, Sur PJ, Fay KA, Cornaby L, Ferrara G, Salama JS, et al. Health effects of dietary risks in 195 countries, 1990-2017: a systematic analysis for the Global Burden of Disease Study 2017. Lancet 2019 May;393(10184):1958-1972. [doi: 10.1016/S0140-6736(19)30041-8]

6. Global strategy on diet, physical activity and health. World Health Organization. 2017. URL: http://www.who.int/ dietphysicalactivity/strategy/eb11344/strategy english web.pdf [accessed 2017-08-21]

7. Ending childhoold obesity. World Health Organization. 2016. URL: http://apps.who.int/iris/bitstream/10665/204176/1/ 9789241510066_eng.pdf?ua=1 [accessed 2022-01-20]

8. Tugault-Lafleur C, Black J. Differences in the quantity and types of foods and beverages consumed by Canadians between 2004 and 2015. Nutrients 2019 Feb 28;11(3):526 [FREE Full text] [doi: 10.3390/nu11030526] [Medline: $\underline{30823448]}$

9. Kirkpatrick SI, Raffoul A, Lee KM, Jones AC. Top dietary sources of energy, sodium, sugars, and saturated fats among Canadians: insights from the 2015 Canadian Community Health Survey. Appl Physiol Nutr Metab 2019 Jun;44(6):650-658 [FREE Full text] [doi: 10.1139/apnm-2018-0532] [Medline: 30951373]

10. Di Cesare M, Sorić M, Bovet P, Miranda JJ, Bhutta Z, Stevens GA, et al. The epidemiological burden of obesity in childhood: a worldwide epidemic requiring urgent action. BMC Med 2019 Nov 25;17(1):212 [FREE Full text] [doi: 10.1186/s12916-019-1449-8] [Medline: 31760948]

11. Scaglioni S, De Cosmi V, Ciappolino V, Parazzini F, Brambilla P, Agostoni C. Factors influencing children's eating behaviours. Nutrients 2018 May 31;10(6):706 [FREE Full text] [doi: 10.3390/nu10060706] [Medline: 29857549]

12. Haines J, Haycraft E, Lytle L, Nicklaus S, Kok FJ, Merdji M, et al. Nurturing children's healthy eating: position statement. Appetite 2019 Jun 01;137:124-133 [FREE Full text] [doi: 10.1016/j.appet.2019.02.007] [Medline: 30797837]

13. Kent MP, Dubois L, Wanless A. Self regulation by industry in food marketing is having little impact during children's preferred television viewing. Can J Diabetes 2011 Jan;35(2):151. [doi: 10.1016/s1499-2671(11)52052-0]

14. Velazquez C, Black J, Kent MP. Food and beverage marketing in schools: a review of the evidence. Int J Environ Res Public Health 2017 Sep 12;14(9):1054 [FREE Full text] [doi: 10.3390/ijerph14091054] [Medline: 28895921]

15. Ronto R, Ball L, Pendergast D, Harris ND. Food literacy at secondary schools in Australia. J Sch Health 2016 Nov 06;86(11):823-831. [doi: 10.1111/josh.12440] [Medline: 27714873]

16. The heavy burden of obesity. Organisation for Economic Co-operation and Development. 2019. URL: https://www.oecd.org/ health/the-heavy-burden-of-obesity-67450d67-en.htm [accessed 2022-01-20]

17. The Lancet Digital Health. Child and adolescent health in the digital age. Lancet Digit Health 2020 Mar;2(3):e102 [FREE Full text] [doi: 10.1016/S2589-7500(20)30029-7] [Medline: 33328079]

18. Prensky M. The games generations: how learners have changed. In: Digital Game-Based Learning. New York: McGraw-Hill Education; 2001.

19. Physical activity and screen time among Canadian children and youth, 2016 and 2017. Statistics Canada. 2019. URL: https:/ /www150.statcan.gc.ca/n1/pub/82-625-x/2019001/article/00003-eng.htm [accessed 2022-01-20]

20. Steeves V. Young Canadian in a wired world: Phase III: trends and recommendations. MediaSmarts. 2015. URL: https:/ /mediasmarts.ca/sites/mediasmarts/files/publication-report/full/ycwwiii trends recommendations fullreport.pdf [accessed 2022-01-20]

21. Guedes SD, Morais RL, Santos LR, Leite HR, Nobre JN, Santos JN. Children's use of interactive media in early childhood - an epidemiological study. Rev Paul Pediatr 2020;38:e2018165 [FREE Full text] [doi: 10.1590/1984-0462/2020/38/2018165] [Medline: $\underline{31778410}$ ]

22. Schumer H, Amadi C, Joshi A. Evaluating the dietary and nutritional apps in the Google Play Store. Healthe Inform Res 2018 Jan;24(1):38-45 [FREE Full text] [doi: 10.4258/hir.2018.24.1.38] [Medline: 29503751]

23. Kabali HK, Irigoyen MM, Nunez-Davis R, Budacki JG, Mohanty SH, Leister KP, et al. Exposure and use of mobile media devices by young children. Pediatrics 2015 Dec 02;136(6):1044-1050. [doi: 10.1542/peds.2015-2151] [Medline: 26527548]

24. Kim SC, Yoon D, Han EK. Antecedents of mobile app usage among smartphone users. J Mark Commun 2014 Aug 22;22(6):653-670. [doi: 10.1080/13527266.2014.951065]

25. Ravyse WS, Blignaut AS, Leendertz V, Woolner A. Success factors for serious games to enhance learning: a systematic review. Virt Real 2016 Sep 20;21(1):31-58. [doi: 10.1007/s10055-016-0298-4]

26. Mulligan C, Kent MP, Christoforou AK, L'Abbé MR. Inventory of marketing techniques used in child-appealing food and beverage research: a rapid review. Int J Public Health 2020 Sep 25;65(7):1045-1055. [doi: 10.1007/s00038-020-01444-w] [Medline: $\underline{\text { 32840633] }}$ 
27. Number of apps available in leading app stores as of 1st quarter 2020. Statista. URL: https://www.statista.com/statistics/ 276623/number-of-apps-available-in-leading-app-stores/ [accessed 2020-09-18]

28. WHO Global Observatory for eHealth. mHealth: New Horizons for Health Through Mobile Technologies: Second Global Survey on eHealth. Geneva: World Health Organization; 2011.

29. Baranowski T, Frankel L. Let's get technical! Gaming and technology for weight control and health promotion in children. Child Obes 2012 Feb;8(1):34-37. [doi: 10.1089/chi.2011.0103] [Medline: 22799477]

30. Thompson D, Bhatt R, Vazquez I, Cullen KW, Baranowski J, Baranowski T, et al. Creating action plans in a serious video game increases and maintains child fruit-vegetable intake: a randomized controlled trial. Int J Behav Nutr Phys Act 2015 Mar;12:39 [FREE Full text] [doi: 10.1186/s12966-015-0199-z] [Medline: 25890060]

31. Cullen KW, Liu Y, Thompson DI. Meal-specific dietary changes from squires quest! II: a serious video game intervention. J Nutr Educ Behav 2016 May;48(5):326-330 [FREE Full text] [doi: 10.1016/j.jneb.2016.02.004] [Medline: 27169641]

32. Holzmann SL, Schäfer H, Groh G, Plecher DA, Klinker G, Schauberger G, et al. Short-term effects of the serious game "Fit, Food, Fun" on nutritional knowledge: a pilot study among children and adolescents. Nutrients 2019 Aug 30;11(9):2031 [FREE Full text] [doi: 10.3390/nu11092031] [Medline: 31480257]

33. Hermans RC, van den Broek N, Nederkoorn C, Otten R, Ruiter EL, Johnson-Glenberg MC. Feed the Alien! The effects of a nutrition instruction game on children's nutritional knowledge and food intake. Games Health J 2018 Jun;7(3):164-174. [doi: 10.1089/g4h.2017.0055] [Medline: 29634366]

34. Froome HM, Townson C, Rhodes S, Franco-Arellano B, LeSage A, Savaglio R, et al. The effectiveness of the foodbot factory mobile serious game on increasing nutrition knowledge in children. Nutrients 2020 Nov 06;12(11):3413 [FREE Full text] [doi: 10.3390/nu12113413] [Medline: 33172094]

35. DeSmet A, Liu Y, De Bourdeaudhuij I, Baranowski T, Thompson D. The effectiveness of asking behaviors among 9-11 year-old children in increasing home availability and children's intake of fruit and vegetables: results from the Squire's Quest II self-regulation game intervention. Int J Behav Nutr Phys Act 2017 Apr 21;14(1):51 [FREE Full text] [doi: 10.1186/s12966-017-0506-y] [Medline: 28431547]

36. Kato-Lin Y, Kumar UB, Prakash BS, Prakash B, Varadan V, Agnihotri S, et al. Impact of pediatric mobile game play on healthy eating behavior: randomized controlled trial. JMIR Mhealth Uhealth 2020 Nov 18;8(11):e15717 [FREE Full text] [doi: 10.2196/15717] [Medline: 33206054]

37. Majumdar D, Koch PA, Lee H, Contento IR, Islas-Ramos AD, Fu D. "Creature-101": a serious game to promote energy balance-related behaviors among middle school adolescents. Games Health J 2013 Oct;2(5):280-290 [FREE Full text] [doi: 10.1089/g4h.2013.0045] [Medline: 24761326]

38. Schoeppe S, Alley S, Van Lippevelde W, Bray NA, Williams SL, Duncan MJ, et al. Efficacy of interventions that use apps to improve diet, physical activity and sedentary behaviour: a systematic review. Int J Behav Nutr Phys Act 2016 Dec 07;13(1):127 [FREE Full text] [doi: 10.1186/s12966-016-0454-y] [Medline: 27927218]

39. Flaherty S, McCarthy M, Collins A, McAuliffe F. Can existing mobile apps support healthier food purchasing behaviour? Content analysis of nutrition content, behaviour change theory and user quality integration. Public Health Nutr 2017 Oct 30;21(2):288-298. [doi: 10.1017/s1368980017002889]

40. Mauch CE, Wycherley TP, Laws RA, Johnson BJ, Bell LK, Golley RK. Mobile apps to support healthy family food provision: systematic assessment of popular, commercially available apps. JMIR Mhealth Uhealth 2018 Dec 21;6(12):e11867 [FREE Full text] [doi: 10.2196/11867] [Medline: $\underline{\text { 30578213] }}$

41. McLean G. Examining the determinants and outcomes of mobile app engagement - A longitudinal perspective. Comput Hum Behav 2018 Jul;84:392-403 [FREE Full text] [doi: 10.1016/j.chb.2018.03.015]

42. Schoeppe S, Alley S, Rebar AL, Hayman M, Bray NA, Van Lippevelde W, et al. Apps to improve diet, physical activity and sedentary behaviour in children and adolescents: a review of quality, features and behaviour change techniques. Int $\mathbf{J}$ Behav Nutr Phys Act 2017 Jun 24;14(1):83 [FREE Full text] [doi: 10.1186/s12966-017-0538-3] [Medline: 28646889]

43. Samdal GB, Eide GE, Barth T, Williams G, Meland E. Effective behaviour change techniques for physical activity and healthy eating in overweight and obese adults; systematic review and meta-regression analyses. Int J Behav Nutr Phys Act 2017 Mar 28;14(1):42 [FREE Full text] [doi: 10.1186/s12966-017-0494-y] [Medline: 28351367]

44. Schoffman DE, Turner-McGrievy G, Jones SJ, Wilcox S. Mobile apps for pediatric obesity prevention and treatment, healthy eating, and physical activity promotion: just fun and games? Transl Behav Med 2013 Sep;3(3):320-325 [FREE Full text] [doi: 10.1007/s13142-013-0206-3] [Medline: 24073184]

45. Kent MP, Pauzé E, Roy E, de Billy N, Czoli C. Children and adolescents' exposure to food and beverage marketing in social media apps. Pediatr Obes 2019 Jun;14(6):e12508 [FREE Full text] [doi: 10.1111/ijpo.12508] [Medline: 30690924]

46. Rose T, Barker M, Maria Jacob C, Morrison L, Lawrence W, Strömmer S, et al. A systematic review of digital interventions for improving the diet and physical activity behaviors of adolescents. J Adolesc Health 2017 Dec;61(6):669-677 [FREE Full text] [doi: 10.1016/j.jadohealth.2017.05.024] [Medline: 28822682]

47. Rivera J, McPherson A, Hamilton J, Birken C, Coons M, Iyer S, et al. Mobile apps for weight management: a scoping review. JMIR Mhealth Uhealth 2016 Jul 26;4(3):e87 [FREE Full text] [doi: 10.2196/mhealth.5115] [Medline: 27460502] 
48. Stoyanov SR, Hides L, Kavanagh DJ, Zelenko O, Tjondronegoro D, Mani M. Mobile app rating scale: a new tool for assessing the quality of health mobile apps. JMIR Mhealth Uhealth 2015 Mar;3(1):e27 [FREE Full text] [doi: 10.2196/mhealth.3422] [Medline: 25760773]

49. Terhorst Y, Philippi P, Sander LB, Schultchen D, Paganini S, Bardus M, et al. Validation of the Mobile Application Rating Scale (MARS). PLoS One 2020 Nov 2;15(11):e0241480 [FREE Full text] [doi: 10.1371/journal.pone.0241480] [Medline: 33137123]

50. Michie S, Richardson M, Johnston M, Abraham C, Francis J, Hardeman W, et al. The behavior change technique taxonomy (v1) of 93 hierarchically clustered techniques: building an international consensus for the reporting of behavior change interventions. Ann Behav Med 2013 Aug;46(1):81-95. [doi: 10.1007/s12160-013-9486-6] [Medline: 23512568]

51. Nouri R, Kalhori SR, Ghazisaeedi M, Marchand G, Yasini M. Criteria for assessing the quality of mHealth apps: a systematic review. J Am Med Inform Assoc 2018 Aug 01;25(8):1089-1098 [FREE Full text] [doi: 10.1093/jamia/ocy050] [Medline: 29788283]

52. Jake-Schoffman DE, Silfee VJ, Waring ME, Boudreaux ED, Sadasivam RS, Mullen SP, et al. Methods for evaluating the content, usability, and efficacy of commercial mobile health apps. JMIR Mhealth Uhealth 2017 Dec 18;5(12):e190 [FREE Full text] [doi: 10.2196/mhealth.8758] [Medline: 29254914]

53. Schmidt-Kraepelin M, Thiebes S, Tran M, Sunyaev A. What's in the game? Developing a taxonomy of gamification concepts for health apps. In: Proceedings of the Hawaii International Conference on System Sciences. 2018 Presented at: Hawaii International Conference on System Sciences; 2018; Waikoloa Village, Hawaii. [doi: 10.24251/hicss.2018.150]

54. Klasnja P, Consolvo S, Pratt W. How to evaluate technologies for health behavior change in HCI research. In: Proceedings of the SIGCHI Conference on Human Factors in Computing Systems. 2011 Presented at: CHI '11: CHI Conference on Human Factors in Computing Systems; May 7 - 12, 2011; Vancouver BC Canada p. 3063-3072. [doi: 10.1145/1978942.1979396]

55. Canada's food guide. Government of Canada - Health Canada. 2019. URL: https://food-guide.canada.ca/en/ [accessed 2022-01-20]

56. Canada's dietary guidelines for health professionals and policy makers. Government of Canada - Health Canada. 2019. URL: https://food-guide.canada.ca/guidelines/ [accessed 2022-01-20]

57. RStudio. RStudio: Integrated Development for R. 2020. URL: http://www,rstudio.com/ [accessed 2022-01-20]

58. Bardus M, van Beurden SB, Smith JR, Abraham C. A review and content analysis of engagement, functionality, aesthetics, information quality, and change techniques in the most popular commercial apps for weight management. Int J Behav Nutr Phys Act 2016;13(1):35 [FREE Full text] [doi: 10.1186/s12966-016-0359-9] [Medline: 26964880]

59. Cheng H, Tutt A, Llewellyn C, Size D, Jones J, Taki S, et al. Content and quality of infant feeding smartphone apps: five-year update on a systematic search and evaluation. JMIR Mhealth Uhealth 2020 May 27;8(5):e17300 [REEE Full text] [doi: $10.2196 / 17300]$ [Medline: $\underline{32459187]}$

60. Smolin L, Grosvenor M, Gurfinkel D. Nutrition: Science and Applications, 3rd Canadian Edition. Hoboken, New Jersey, United States: John Wiley \& Sons; 2020.

61. Sadeghirad B, Duhaney T, Motaghipisheh S, Campbell NR, Johnston BC. Influence of unhealthy food and beverage marketing on children's dietary intake and preference: a systematic review and meta-analysis of randomized trials. Obes Rev 2016 Oct 18;17(10):945-959. [doi: 10.1111/obr.12445] [Medline: 27427474]

62. Dorey E, McCool J. The role of the media in influencing children's nutritional perceptions. Qual Health Res 2009 May 03;19(5):645-654. [doi: 10.1177/1049732309334104] [Medline: 19380500]

63. Story M, Kaphingst KM, Robinson-O'Brien R, Glanz K. Creating healthy food and eating environments: policy and environmental approaches. Annu Rev Public Health 2008 Apr;29(1):253-272. [doi: 10.1146/annurev.publhealth.29.020907.090926] [Medline: 18031223 ]

64. Cairns G, Angus K, Hastings G, Caraher M. Systematic reviews of the evidence on the nature, extent and effects of food marketing to children. A retrospective summary. Appetite 2013 Mar;62:209-215 [FREE Full text] [doi:

10.1016/j.appet.2012.04.017] [Medline: 22561190]

65. Hingle M, Patrick H. There are thousands of apps for that: navigating mobile technology for nutrition education and behavior. J Nutr Educ Behav 2016 Mar;48(3):213-218. [doi: 10.1016/i.jneb.2015.12.009] [Medline: 26965099]

66. Wharton CM, Johnston CS, Cunningham BK, Sterner D. Dietary self-monitoring, but not dietary quality, improves with use of smartphone app technology in an 8-week weight loss trial. J Nutr Educ Behav 2014 Sep;46(5):440-444. [doi: 10.1016/j.jneb.2014.04.291] [Medline: 25220777]

67. Brick TR, Mundie J, Weaver J, Fraleigh R, Oravecz Z. Low-burden mobile monitoring, intervention, and real-time analysis using the Wear-IT framework: example and usability study. JMIR Form Res 2020 Jun 17;4(6):e16072 [FREE Full text] [doi: 10.2196/16072] [Medline: $\underline{32554373}$ ]

68. Rathbone AL, Prescott J. The use of mobile apps and SMS messaging as physical and mental health interventions: systematic review. J Med Internet Res 2017 Aug 24;19(8):e295 [FREE Full text] [doi: 10.2196/jmir.7740] [Medline: 28838887]

69. Berrouiguet S, Baca-García E, Brandt S, Walter M, Courtet P. Fundamentals for future mobile-health (mHealth): a systematic review of mobile phone and web-based text messaging in mental health. J Med Internet Res 2016 Dec 10;18(6):e135 [FREE Full text] [doi: 10.2196/jmir.5066] [Medline: 27287668] 
70. Dovaliene A, Masiulyte A, Piligrimiene Z. The relations between customer engagement, perceived value and satisfaction: the case of mobile applications. Procedia Soc Behav Sci 2015 Dec;213:659-664 [FREE Full text] [doi: 10.1016/j.sbspro.2015.11.469]

71. Brown JM, Savaglio R, Watson G, Kaplansky A, LeSage A, Hughes J, et al. Optimizing child nutrition education with the foodbot factory mobile health app: formative evaluation and analysis. JMIR Form Res 2020 Apr 17;4(4):e15534 [FREE Full text] [doi: 10.2196/15534] [Medline: $\underline{32301743}$ ]

72. Santo K, Richtering SS, Chalmers J, Thiagalingam A, Chow CK, Redfern J. Mobile phone apps to improve medication adherence: a systematic stepwise process to identify high-quality apps. JMIR Mhealth Uhealth 2016 Dec 02;4(4):e132 [FREE Full text] [doi: 10.2196/mhealth.6742] [Medline: 27913373]

73. Zarnowiecki D, Mauch CE, Middleton G, Matwiejczyk L, Watson WL, Dibbs J, et al. A systematic evaluation of digital nutrition promotion websites and apps for supporting parents to influence children's nutrition. Int J Behav Nutr Phys Act 2020 Feb 10;17(1):17 [FREE Full text] [doi: 10.1186/s12966-020-0915-1] [Medline: 32041640]

74. Melbye EL, Øverby NC, Øgaard T. Child consumption of fruit and vegetables: the roles of child cognitions and parental feeding practices. Public Health Nutr 2011 Oct 17;15(6):1047-1055. [doi: 10.1017/s1368980011002679]

75. de la Vega R, Miró J. mHealth: a strategic field without a solid scientific soul. A systematic review of pain-related apps. PLoS One 2014 Jul;9(7):e101312 [FREE Full text] [doi: 10.1371/journal.pone.0101312] [Medline: 24999983]

76. Bender JL, Yue RYK, To MJ, Deacken L, Jadad AR. A lot of action, but not in the right direction: systematic review and content analysis of smartphone applications for the prevention, detection, and management of cancer. J Med Internet Res 2013 Dec;15(12):e287 [FREE Full text] [doi: 10.2196/jmir.2661] [Medline: 24366061]

\title{
Abbreviations \\ BCT: behavior change technique \\ CFG: Canada's Food Guide \\ MARS: Mobile App Rating Scale \\ mHealth: mobile health
}

\author{
Edited by L Buis; submitted 24.06.21; peer-reviewed by I Gabashvili, U Bork; comments to author 28.10.21; revised version received \\ 04.11.21; accepted 21.12.21; published 16.02.22 \\ Please cite as: \\ Brown JM, Franco-Arellano B, Froome H, Siddiqi A, Mahmood A, Arcand J \\ The Content, Quality, and Behavior Change Techniques in Nutrition-Themed Mobile Apps for Children in Canada: App Review and \\ Evaluation Study \\ JMIR Mhealth Uhealth 2022;10(2):e31537 \\ URL: https://mhealth.jmir.org/2022/2/e31537 \\ doi: 10.2196/31537 \\ PMID:
}

(CJacqueline Marie Brown, Beatriz Franco-Arellano, Hannah Froome, Amina Siddiqi, Amina Mahmood, JoAnne Arcand. Originally published in JMIR mHealth and uHealth (https://mhealth.jmir.org), 16.02.2022. This is an open-access article distributed under the terms of the Creative Commons Attribution License (https://creativecommons.org/licenses/by/4.0/), which permits unrestricted use, distribution, and reproduction in any medium, provided the original work, first published in JMIR mHealth and uHealth, is properly cited. The complete bibliographic information, a link to the original publication on https://mhealth.jmir.org/, as well as this copyright and license information must be included. 